\title{
IMPLEMENTATION OF LEAN PRINCIPLES TO IMPROVE THE OPERATIONS OF A SALES WAREHOUSE IN THE MANUFACTURING INDUSTRY
}

\author{
Bibin Baby ${ }^{1 *}$, Prasanth $\mathrm{N}^{1}$, D. Selwyn Jebadurai ${ }^{1}$ \\ ${ }^{1}$ Department of Mechanical Engineering, Kattankulathur Campus, SRM Institute of Science and \\ Technology, Kattankulathur 603203, Tamil Nadu, India
}

(Received: December 2016 / Revised: March 2017 / Accepted: January 2018)

\begin{abstract}
This paper deals with the implementation of lean techniques in a sales warehouse in the manufacturing industry. It highlights efforts to improve warehouse operations by eliminating waste using lean tools such as a value stream map (VSM). A current state VSM exposes waste in an existing system. High order picking time, improper storage, delay in vehicle loading, and low space utilization make the warehouse inefficient. Implementation of a U-shaped flow layout in the warehouse improves order picking time, vehicle loading time, and space utilization. A future state VSM shows the new state of operations before implementation. After lean implementation, considerable improvements were observed in vehicle loading, space utilization, and storage. Thus, the efficiency of warehouse operations is increased, resulting in quicker responses to customers' demands.
\end{abstract}

Keywords: $\quad$ ABC analysis; Layout; Lean manufacturing; Value stream mapping; Warehouse

\section{INTRODUCTION}

In the modern era, prolonged production runs, unfinished work, and extensive lead times are becoming detrimental. Industries should be flexible enough to meet customers' demands. The main issue faced by manufacturers today is how to deliver high-quality products or services quickly at a low cost. Industries are looking for new tools and techniques to produce goods to compete and survive in the market. One promising method for addressing this issue is the application of lean principles and techniques. Lean manufacturing, simply known as "lean," is a production practice that identifies waste in existing activities and eliminates them so as to achieve continuous improvement and better productivity (Fullerton et al., 2014; Chiabert et al., 2015). The wastes to be eliminated include overproduction, excess inventory, delay, transportation, reworking, and underutilization of people and facilities. Elimination of waste can lead to better connectivity between operations. In addition, it improves the response time to customers' demands, reduces inventory, reduces cost, and improves productivity (Yang et al., 2015). Waste is eliminated using various lean tools, such as 5S, value stream maps (VSMs), and Kanban and Kaizen (Khamis et al., 2009; Arslankaya \& Atay, 2015; Jiménez et al., 2015). This paper mainly utilizes VSM and layout changes to solve problems.

VSM is a method to identify non-value-added activities in an existing operation (Venkataraman et al., 2014; Rohac \& Janusuka, 2015). It represents activities in a flow chart manner. There are two types of VSMs: current state and future state maps (Abdulmalek \& Rajgopal, 2007; Suhadak $\&$ Amit, 2015). A current state map is drawn after observing current activities, and it

\footnotetext{
${ }^{*}$ Corresponding author's email: bibinbaby12345@gmail.com, Tel: +91-8281441928, Fax: +91-04862-258428 Permalink/DOI: https://dx.doi.org/10.14716/ijtech.v9i1.1161
} 
helps to identify all wasteful activities. Then, a future state map is drawn to show the effect of eliminating all wasteful activities (Rohani \& Zahraee, 2015). VSM helps identify bottlenecks, waste within processes, and the sequence of activities. Compared to other lean techniques, it is inexpensive, easy to implement, quick, and easy to learn.

The literature reveals that implementing lean principles results in better productivity and is very helpful for meeting customer demands. However, to the best of the author's knowledge, the literature regarding implementation of lean principles in warehouse operations is very limited. Hence, in this work, effort is made to improve sales warehouse operations so as to meet customer demands as quickly as possible using lean principles. Warehouses are important areas when dealing with customer demands (Bortolini et al., 2015). They are material handling stations dedicated to receiving, storage, order picking, dispatching, docking, and shipping of goods (van den Berg \& Zijm, 1999). Receiving involves scanning the product package and entering it into database, while storage involves storing products in the desired arrangement. Products are picked based on customer orders, stored in a particular area to await delivery, and then scanned in the dispatching area before shipping. Warehouses can be generally classified into three types: production warehouse, distribution warehouse, and contract warehouse (Dotoli et al., 2015). The wastes identified in these warehouses are divided into transportation, inventory, waiting, delay, space, movement, overproduction, and defect wastes. Transportation, waiting, delay, space, defect, and movement wastes are generally eliminated by layout changes, proper working rules, visual management tools, and 5S(sort, set in order, shine, standardize, sustain). Inventory can be made more efficient by adopting proper inventory models such as $\mathrm{ABC}$ analysis. This paper considers the sales warehouse to be a symbol for various issues related to distribution of products to customers.

The objective of this work is to provide lean solutions to improve warehouse operations. Using lean tools such as VSM, wastes are identified. Methods for eliminating wastes are decided and a future state VSM is drawn. The solutions mostly involve layout changes drawn in Autodesk inventor. A class-based storage system using $\mathrm{ABC}$ analysis is developed to reduce travel waste.

\section{METHODOLOGY}

Of the available lean tools, such as 5S and Kanban and Kaizen, VSM is selected for this work as the others are not as helpful for identifying wastes in a process. Its advantages, such as its ability to find bottlenecks, easy implementation, and simple learning curve, make it an ideal way to solve problems in a warehouse. The methodology of this work is divided into three phases: study of an existing system, development of lean solutions, and results (Tyagi et al., 2015). In the study of an existing system, the problem area (i.e., sales warehouse) is identified. For evaluation of the current state of the system, a detailed study is performed. Time and motion studies are used to monitor each warehouse operation. From these studies, a current state VSM is drawn. Wastes that hinder smooth operation of the warehouse are identified from the VSM. In the development of lean solutions phase, solutions for eliminating wastes - changes in layout and inventory arrangement - are developed. The new inventory arrangement is based upon ABC inventory analysis; products are arranged according to the customers' contribution to product sales. The warehouse layout is changed from an $\mathrm{L}$ shape to a $\mathrm{U}$ shape, which minimizes the travel distance and time required for operation.

A future state VSM is drawn to show the future state of warehouse and progress of operations based on the lean solutions. In the implementation stage, the developed lean solutions are implemented. The result phase mainly consists of evaluation and analysis of the new state. During this evaluation, the results of implementation of lean solutions are monitored using time and motion studies. Analysis is performed to determine whether the lean solutions are successful. 


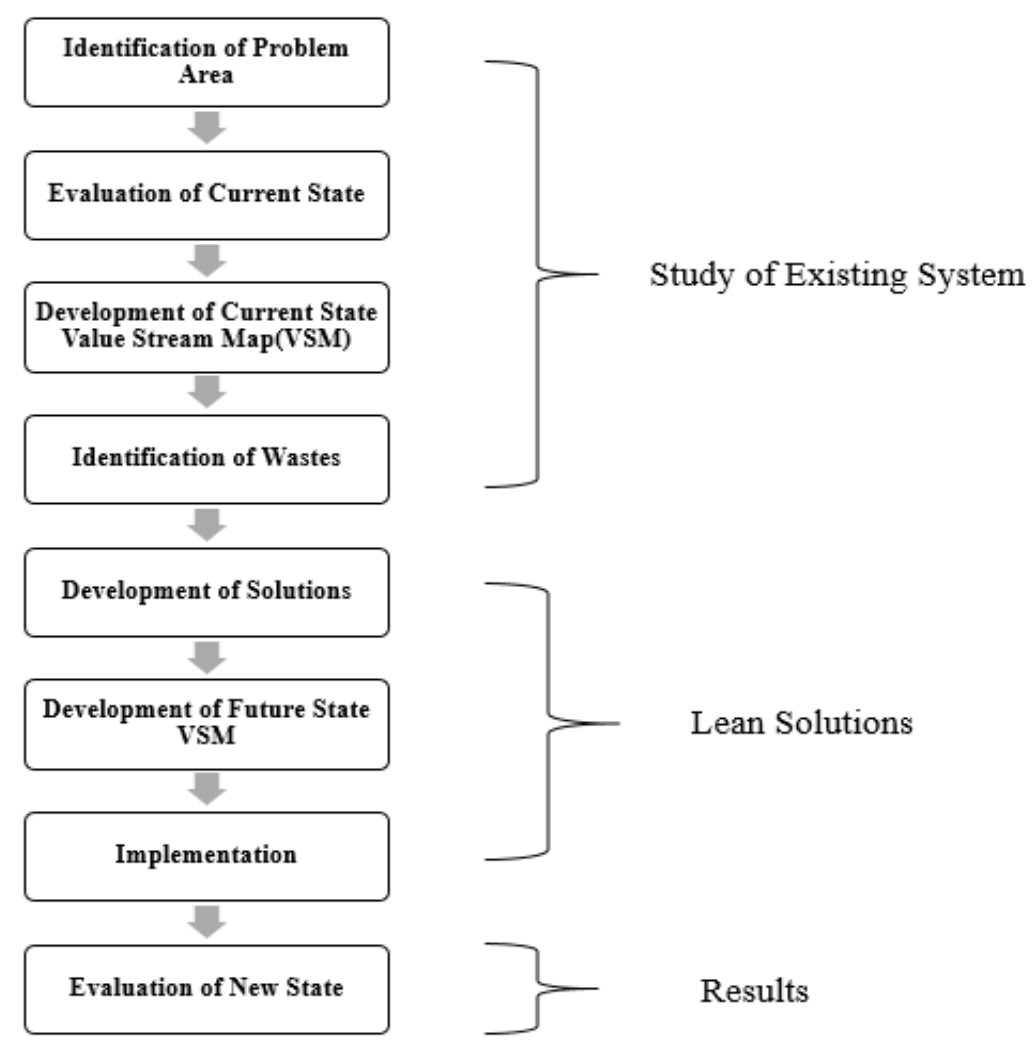

Figure 1 Methodology

\section{CASE STUDY}

This paper describes the application of lean techniques in a sales warehouse of a reputed manufacturing company in India. There are five value streams with which products are associated: actuators, boosters, compressors, anti-lock braking systems (ABSs) and valves. The products, which are packed in carton boxes and pallets, enter the warehouse from the assembly line.

\subsection{Study of Existing System}

Figure 2 shows a model of the existing state of the warehouse created using Autodesk Inventor. Packed products come from the assembly line. There are two docks in which parts are loaded.

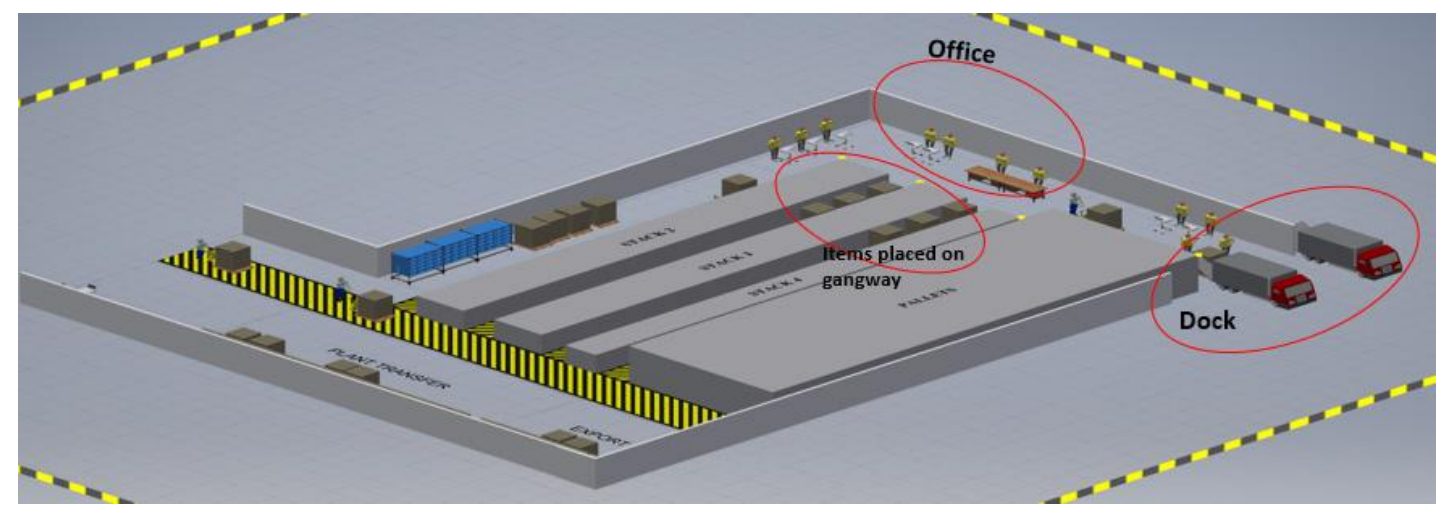

Figure 2 Existing layout

The warehouse has an L-shaped layout in which the receiving area and dock are on different ends. Order picking is performed after vehicle arrival, causing delay in vehicle loading. 
Material stacking based on the value stream increased picking time. Picked products placed on gangways obstructed motion. From the collected data, a current state VSM was drawn. Figure 3 shows the current state VSM.

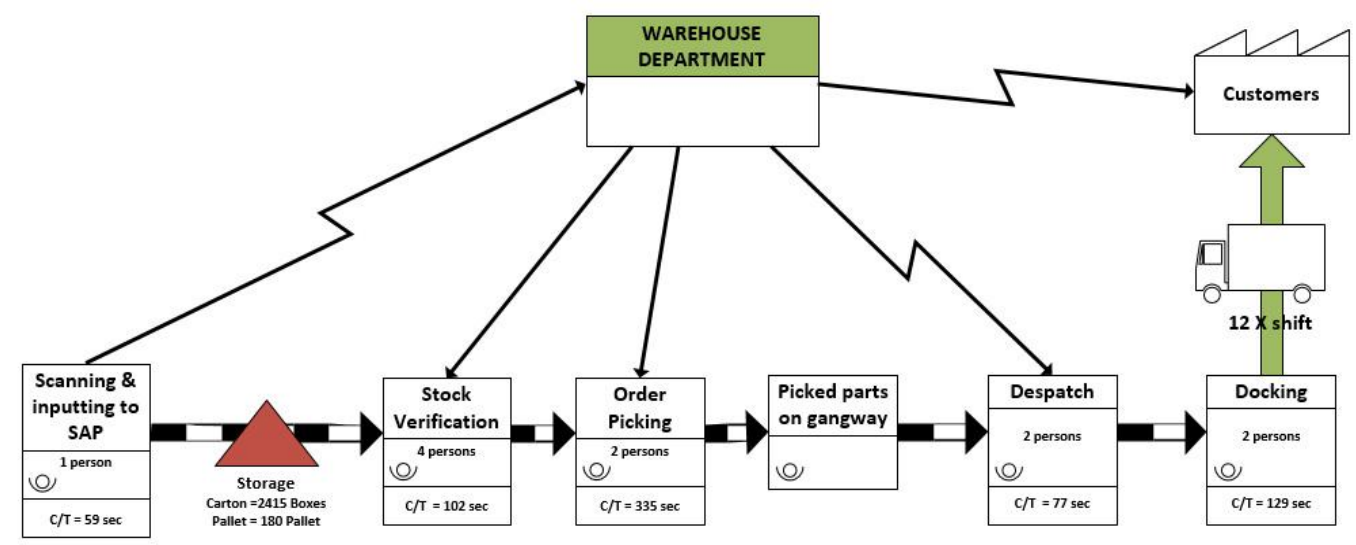

Figure 3 Current state value stream map

Scanning, storing, stock verification, order picking, dispatching, and docking are the main operations of the warehouse. The cycle time for each operation is determined by time study. The figure clearly shows that order picking requires the most time (335 s) and thus is a waste that must be reduced. After order picking, items are placed on the gangway, obstructing movement of materials. Table 1 shows the identified wastes, and its location.

Table 1 Waste identification

\begin{tabular}{cll}
\hline Sl. No. & \multicolumn{1}{c}{ Waste } & \multicolumn{1}{c}{ Location } \\
\hline 1 & Delayed scanning & Receiving area \\
2 & Delay in movements & Gangway \\
3 & High vehicle loading time & Dock \\
4 & Unnecessary movement during storing and order picking & Storage area \\
\hline
\end{tabular}

The observed wastes are delayed scanning, obstructed material flow, improper storage, delayed storage, high order picking, and delayed vehicle loading. Improper storage directly causes high order picking time and delayed vehicle loading.

\subsection{Lean Solutions}

In this phase, solutions for the identified wastes are developed. Table 2 shows the wastes, their locations, and ways to eliminate them.

Table 2 Waste solutions

\begin{tabular}{clll}
\hline Sl. No. & \multicolumn{1}{c}{ Waste } & \multicolumn{1}{c}{ Location } & \multicolumn{1}{c}{ Solutions } \\
\hline 1 & Delayed scanning & Receiving area & Move scanning area \\
& & nearer to gangway \\
2 & Delay in movements & Gangway & Two-way gangway \\
3 & High vehicle loading time & Dock & Marshal yard \\
4 & Unnecessary movement during storing and & Storage area & U-shaped flow layout \\
& & using ABC analysis \\
\hline
\end{tabular}

The delay in scanning is due to the $7.5 \mathrm{~m}$ distance between the scanning area and products. Thus, the operator has to move $15 \mathrm{~m}$ for each scanning and data entry activity. To reduce scanning time, 
the scanning area is moved nearer to the gangway. The new distance between the scanning area and products is $1 \mathrm{~m}$.

Material obstruction mainly occurs due to the clash between inward and outward flow and can be solved by a two-way gangway. By following the directional arrows, the clash between inward and outward flow will be reduced. Figures $4 \mathrm{a}$ and $4 \mathrm{~b}$ show the current gangway and two-way gangway, respectively.

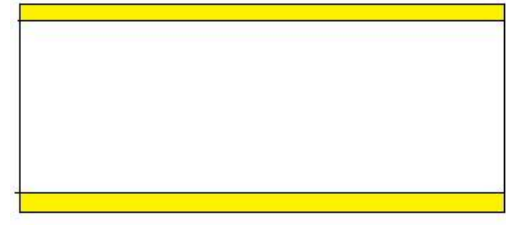

(a)

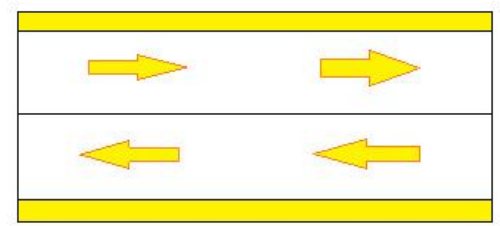

(b)

Figure 4 (a) Current gangway; and (b) two-way gangway

High vehicle loading time is another waste that should be eliminated. In the previous layout, shown in Figure 2, order picking was done only after a vehicle entered the docking area. In total, it takes nearly $63 \mathrm{~min}$ to load the vehicle. Nearly 20 vehicles come to warehouse per shift. But, in the current scenario, it is possible to load only 12 vehicles. Also, picked products were placed on the gangway, obstructing flow. To solve this, a marshal yard was implemented, as shown in Figure 5.

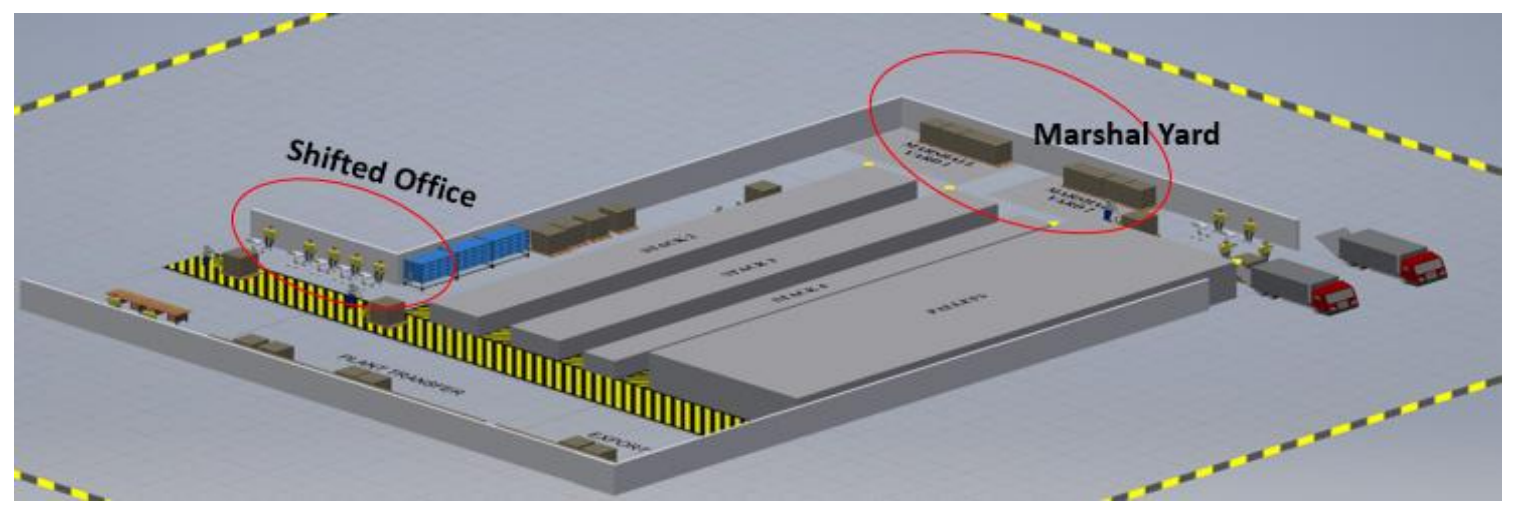

Figure 5 Marshal yard implementation

In order to reduce vehicle loading time, the new layout includes two marshal yards so that order picking is done at least 1 hour before a vehicle arrives. As a result, vehicle loading takes only 16 min.

Unnecessary movement during storing and order picking is the next waste that is targeted. Figure 2 shows the current layout, in which material flows in an $\mathrm{L}$ shape. The dock and receiving area are at different ends of the warehouse, meaning that each product has to travel $67.5 \mathrm{~m}$ before loading. Thus, much manpower is wasted moving the parts.

In the new layout, the flow has a reverse U-shaped layout and items to be stored are classified into three categories based on $\mathrm{ABC}$ analysis. This layout provides excellent cross-docking as the cross-docking distance is reduced to $30 \mathrm{~m}$ (previously $67.5 \mathrm{~m}$ ). " $\mathrm{A}$ " items should be placed nearer to dock area, while "B" and "C" items should be stacked afterwards. Figure 6 shows the U-shaped flow layout. 


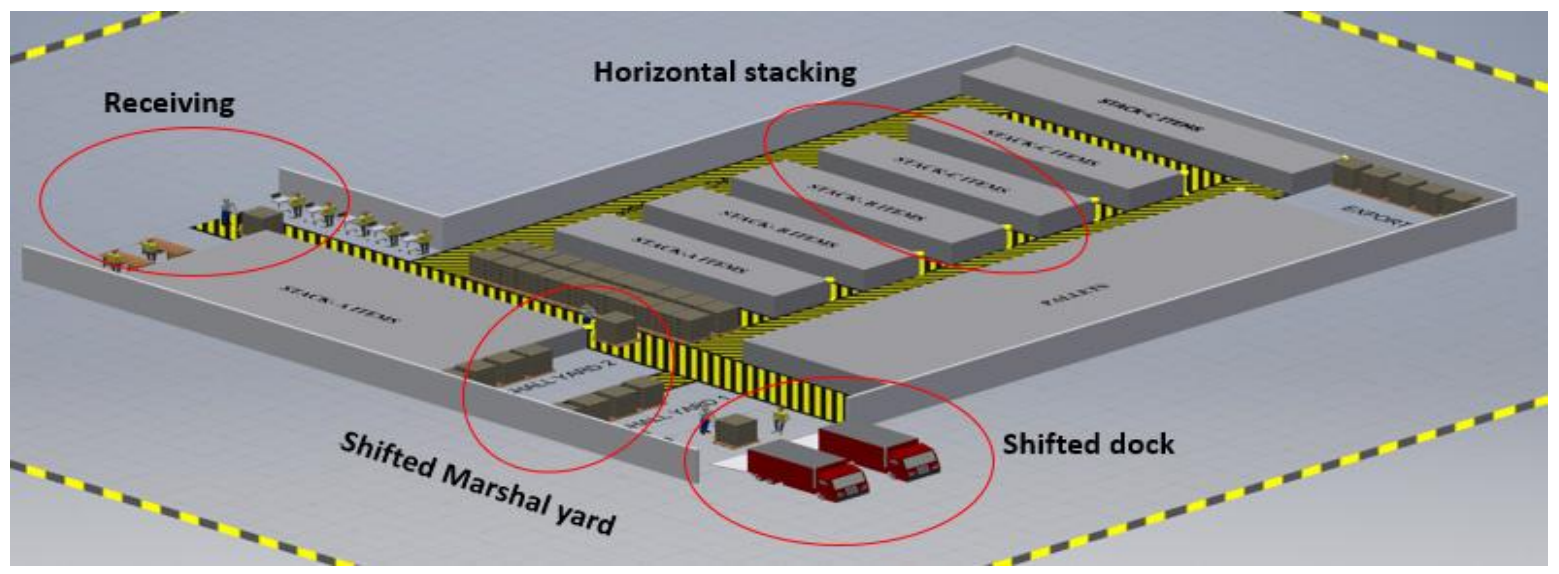

Figure 6 U-shaped flow layout

$\mathrm{ABC}$ storage analysis is used to reduce order picking time. It is a method of storage categorization in which items are classified into three classes: A, B, and C. Figure 7 shows an ABC analysis graph of the sales value of products sold to customers.

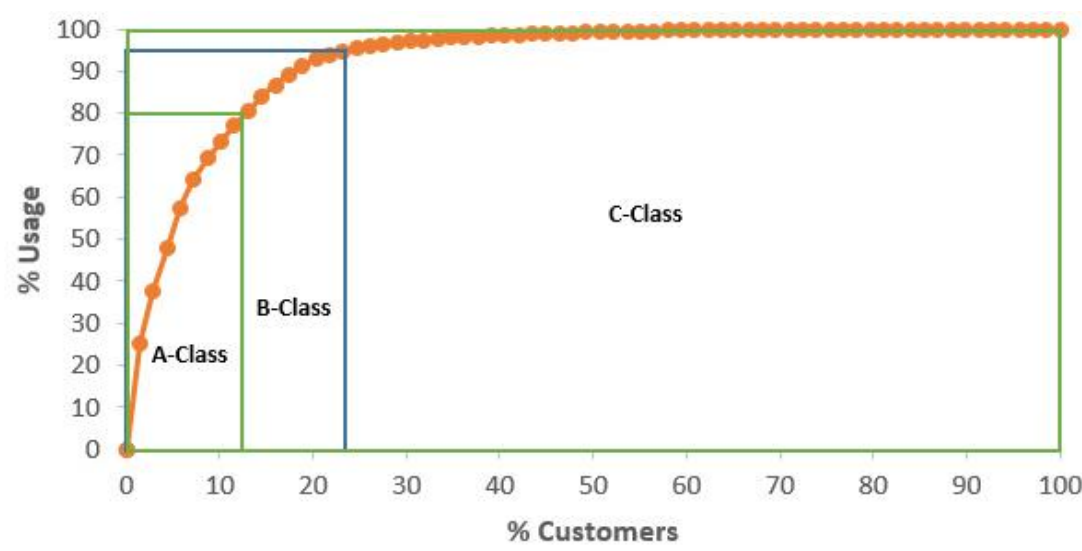

Figure $7 \mathrm{ABC}$ analysis

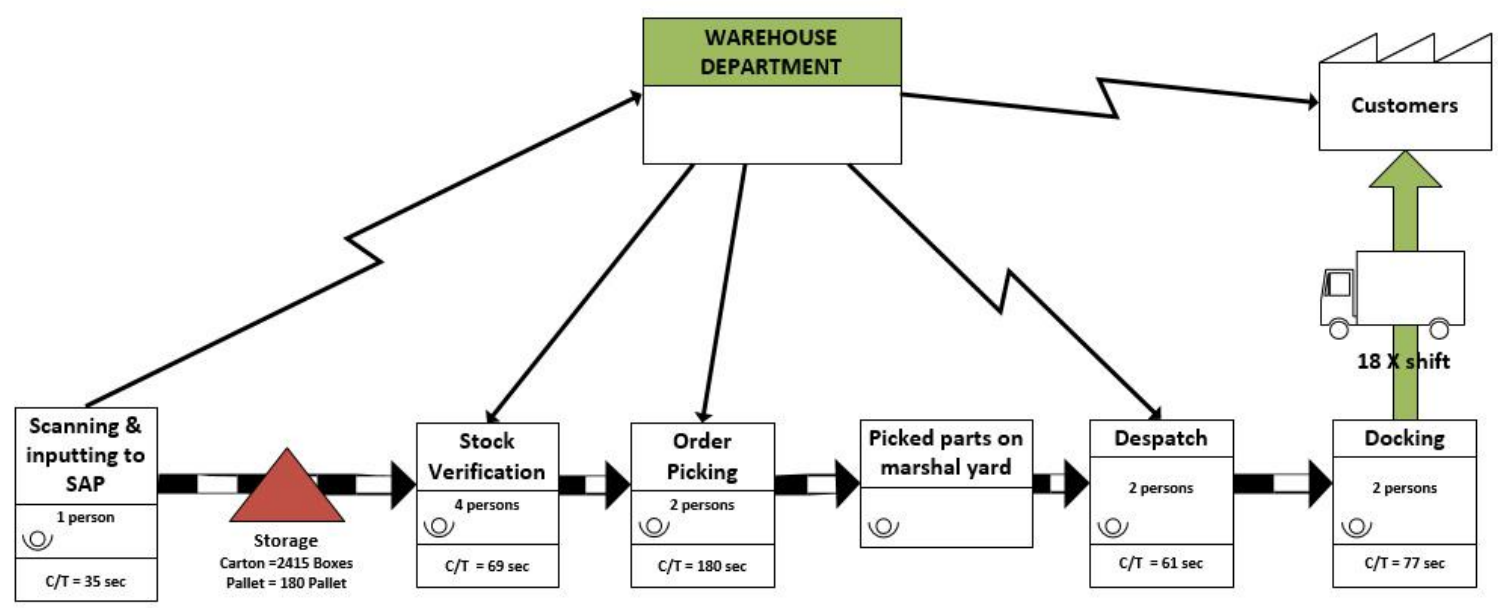

Figure 8 Future state value stream map

In Figure 7, customers are classified into three classes based on their contribution to the total sales value. The A class is the most important and is responsible for $80 \%$ of the total sales value, while the $\mathrm{B}$ class is responsible for $15 \%$ of the total sales value and the $\mathrm{C}$ class is responsible for 
$5 \%$ of the total sales value. The A class consists of $13 \%$ of customers, the B class consists of $11 \%$ of customers, and the $\mathrm{C}$ class consists of $76 \%$ of customers. Since the demand of the A class is higher, it is better to place those products nearer to the dock area than B and C class products.

Based on the solutions and their results, a future state VSM was drawn, as shown in Figure 8. This map shows the future state before implementation. Picked products are placed in the marshal yard instead of on the gangway, and the cycle time of each operation is reduced.

\section{RESULTS AND DISCUSSION}

Each warehouse operation is improved by value stream mapping and layout changes. Figure 9 shows the operation times of the previous layout and new layout.

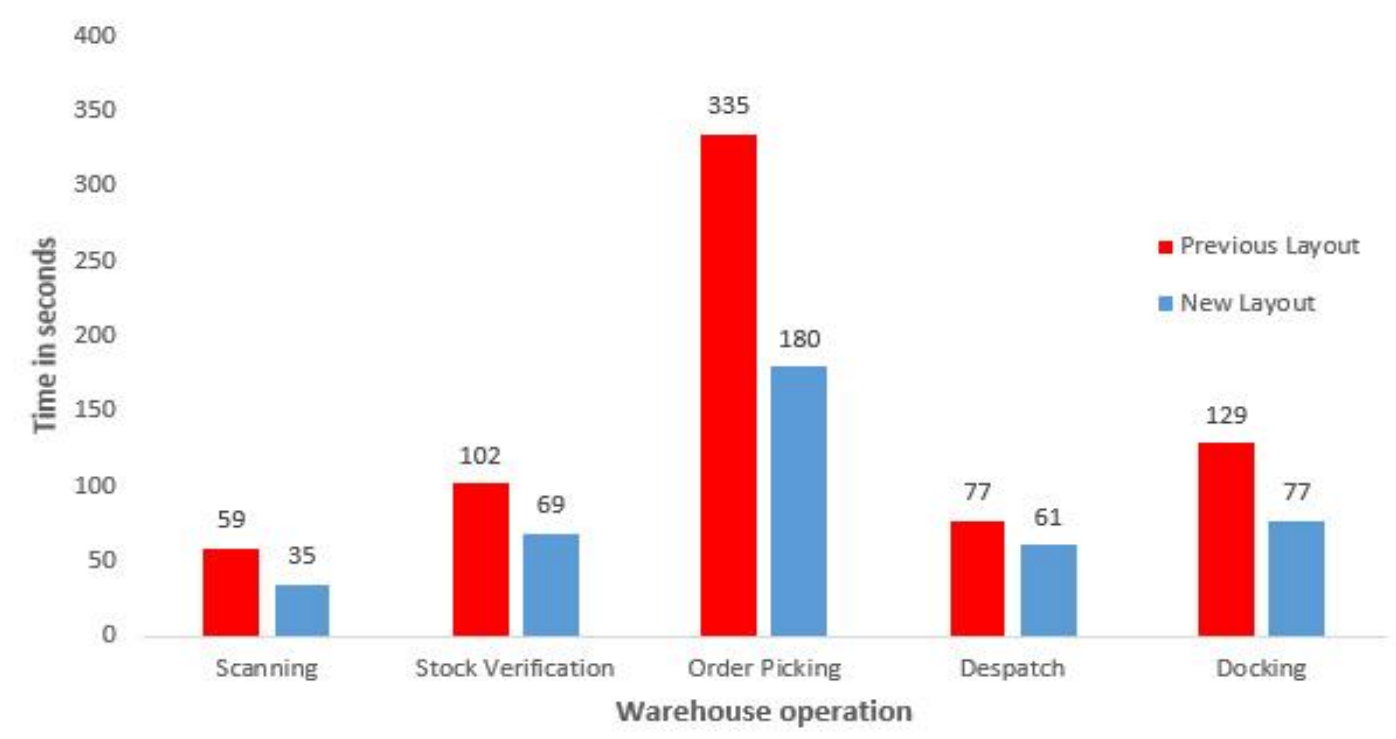

Figure 9 Improvement in warehouse operations

The graph clearly shows that efficiency of operations is improved in the new layout. Scanning time is reduced from 59 to $35 \mathrm{~s}$, and stock verification time is reduced from 102 to $69 \mathrm{~s}$. Order picking time, which was previously $335 \mathrm{~s}$, was reduced to $180 \mathrm{~s}$ by $\mathrm{ABC}$ inventory analysis. Dispatching was reduced from 77 to $61 \mathrm{~s}$, and docking was reduced from 129 to $77 \mathrm{~s}$ by the marshal yard.

Table 3 Results

\begin{tabular}{clc}
\hline Sl. No. & Operation & \% of time reduced \\
\hline 1 & Scanning & $40.67 \%$ \\
2 & Stock verification & $32.35 \%$ \\
3 & Order picking & $46.26 \%$ \\
4 & Dispatch & $20.77 \%$ \\
5 & Docking & $40.31 \%$ \\
\hline
\end{tabular}

Table 3 shows the results of the VSM and layout change solutions. Scanning time was reduced by $40.67 \%$, stock verification was reduced by $32.35 \%$, and order picking time was reduced by $46.26 \%$ due to the U-shaped layout. In addition, the marshal yard reduced vehicle loading, docking, and dispatching time. 
Table 4 Improvement in vehicle loading

\begin{tabular}{clcc}
\hline Sl. No & \multicolumn{1}{c}{ Factors } & Previous layout & New layout \\
\hline 1 & Vehicle loading time in minutes & $63 \mathrm{~min}$ & $16 \mathrm{~min}$ \\
2 & $\%$ reduction in time & --- & $74.60 \%$ \\
\hline
\end{tabular}

Table 4 shows that marshal yard implementation reduced vehicle loading time by $74.6 \%$. In the previous layout, vehicle loading took $63 \mathrm{~min}$, while after implementation it took only $16 \mathrm{~min}$.

Table 5 Benefits of U-shaped flow layout

\begin{tabular}{clccc}
\hline Sl. No. & \multicolumn{1}{c}{ Factor } & $\begin{array}{c}\text { Current } \\
\text { layout }\end{array}$ & $\begin{array}{c}\text { U-shaped flow } \\
\text { layout }\end{array}$ & $\begin{array}{c}\% \text { of improvement or } \\
\text { reduction }\end{array}$ \\
\hline 1 & Cross docking distance $(\mathrm{m})$ & $67.5 \mathrm{~m}$ & $30 \mathrm{~m}$ & $55.5 \%$ reduce \\
2 & Storage area $\left(\mathrm{m}^{2}\right)$ & $482.625 \mathrm{~m}^{2}$ & $502.5 \mathrm{~m}^{2}$ & $4.11 \%$ improve \\
3 & No. of storage locations & 515 & 536 & $4.07 \%$ improve \\
\hline
\end{tabular}

The benefits of a U-shaped flow layout are listed in Table 5. The cross-docking distance (distance from the receiving area to dock) is reduced from $67.5 \mathrm{~m}$ to $30 \mathrm{~m}$ in the new layout. Thus, for fastmoving products (products with the highest demand), the travelling distance is reduced by 55.5\%. In addition, storage area is increased from $482.625 \mathrm{~m}^{2}$ to $502.5 \mathrm{~m}^{2}$ (a $4.11 \%$ improvement) and the number of storage locations is increased from 515 to 536 (a $4.07 \%$ improvement).

\section{CONCLUSION}

As part of a continuous improvement process, an attempt was made to improve the efficiency of the operations of a warehouse in the manufacturing industry using lean principles. Value stream mapping was used to track waste, and most types of operation waste, such as high order picking time, delayed vehicle loading, and improper storage, are eliminated by changing to a U-shaped flow layout and performing ABC inventory analysis. The majority of warehouse operations are improved by at least $40 \%$. A future state map is drawn based upon the solutions showed the improvement in processes. This paper shows that lean principles can be successfully applied to warehouses as well as shop floors.

\section{REFERENCES}

Abdulmalek, F.A., Rajgopal, J., 2007. Analyzing the Benefits of Lean Manufacturing and Value Stream Mapping Via Simulation: A Process Sector Case Study. International Journal of Production Economics, Volume 107(1), pp. 223-236

Arslankaya, S., Atay, H., 2015. Maintenance Management and Lean Manufacturing Practices in a Firm Which Produces Dairy Products. Procedia-Social and Behavioural Sciences, Volume 207, pp. 214-224

Bortolini, M., Faccio, M., Gamberi, M., Manzini, R., 2015. Diagonal Cross Aisles in Unit Load Warehouses to Increase Handling Performance. International Journal of Production Economics, Volume 170 Part C, pp. 838-849

Chiabert, P., Antonio, G.D., Inoyatkhodjaev, J., Lombardi, F., Ruffa, S., 2015. Improvement of Powertrain Mechatronic Systems for Lean Automotive Manufacturing. Procedia CIRP, Volume 33, pp. 53-58

Dotoli, M., Epicoco, N., Falagario, M., Costantino, N., Turchiano, B., 2015. An Integrated Approach for Warehouse Analysis and Optimization: A Case Study. Computers in Industry, Volume 70, pp. 56-69 
Fullerton, R.R., Kennedy, F.A., Widener, S.K., 2014. Lean Manufacturing and Firm Performance: The Incremental Contribution of Lean Management Practices. Journal of Operations Management, Volume 32(7-8), pp. 414-428

Jiménez, M., Romero, L., Dominguez, M., del Mar Espinosa, M., 2015. 5S Methodology Implementation in the Laboratories of an Industrial Engineering University School. Safety Science, Volume 78, pp. 163-172

Khamis, N., Abrahman, M.N., Jamaludin, K.R., Ismail, A.R., Ghani, J.A., Zulkifli, R., 2009. Development of 5S Practice Checklist for Manufacturing Industry. World Congress on Engineering, Volume 1, pp. 978-988

Rohac, T., Janusuka, M., 2015. Value Stream Mapping a Real Case Study. Procedia Engineering, Volume 100, pp. 520-529

Rohani, J.M., Zahraee, S.M., 2015. Production Line Analysis via Value Stream Mapping: A Lean Manufacturing Process of Color Industry. Procedia Manufacturing, Volume 2, pp. 6-10

Suhadak, N.S., Amit, N., 2015. Facility Layout for SME Food Industry via Value Stream Mapping and Simulation. Procedia Economics and Finance, Volume 31, pp. 797-802

Tyagi, S., Choudhary, A., Cai, X., Yang, K., 2015. Value Stream Mapping to Reduce the Leadtime of a Product Development Process. International Journal of Production Economics, Volume 160, pp. 202-212

Van den Berg, J.P., Zijm, W.H.M., 1999. Models for Warehouse Management: Classification and Examples. International Journal of Production Economics, Volume 59(1-3), pp. 519-528

Venkataraman, K., Vijaya Ramnath, B., Muthu Kumar, V., Elanchezhian, C., 2014. Application of Value Stream Mapping for Reduction of Cycle Time in a Machining Process. Procedia Materials Science, Volume 6, pp. 1187-1196

Yang, T., Kuo, Y., Su, C.-T., Hou, C.-L., 2015. Lean Production System Design for Fishing Net Manufacturing using Lean Principles and Simulation Optimization. Journal of Manufacturing Systems, Volume 34, pp. 66-73 